\title{
A Study on the Worker's Consciousness of Settlement according to Innovative Cities
}

\author{
$\mathrm{Na}-\mathrm{Na}$ Lee $^{1}$ and Seung-Wan $\mathrm{Ju}^{2}$ \\ Dept of Financial Accounting/Real Estate, Dong-Eui University, Busan, Korea \\ ${ }^{1}$ sk2342@nate.com, ${ }^{2}$ gauace@naver.com
}

\begin{abstract}
This study explored that based on the premise that family migration rate and housing settlement of the previous agency employees will act as important variables in the plan for relocating public institutions, the ratio of family ownership and relocation of employees to the innovative city was reviewed. The analysis results are summarized as follows. First, analysis of migration patterns by gender of survey respondents shows that there are many cases where married men choose to move their entire family over single body share, while the proportion of their total household share over single body share significantly diminishes as for married women. Second, if the subjects supposed to move is single, they prioritize better surroundings around their corporations and working areas including well developed infrastructure such as cultural facilities, hospital, and transportation. Third, married people, especially for married couples who chose to move to the whole family out of innovative cities, cited the improvement of education standards as the most necessary requirement. The relocation of Busan-based institutions seems to have moved from the capital city, and its employees are reluctant to change their children's educational environment and express concerns about disadvantages from worse school district and decline of educational quality, compared to those in the metropolitan area. Fourth, the survey respondents mentioned their satisfaction with all public domains in their previous residence with those in innovative cities. The survey found that the higher their satisfaction level of the previous residence is, the less likely they are to reside in the innovation cities.
\end{abstract}

Keywords: Innovation city, Public institution, Residence settlement, Residential environment, Innovation city of Busan

\section{Introduction}

The relocation of public institutions was expected to contribute to the larger economic development of underdeveloped region by encouraging population influx to innovative cities.

However, the cities had been developed in relatively short time in accordance to several political consideration by the government rather than in consideration of regional demand and traits, which caused other municipal problems in the existing areas by failing to contemplate several deeply layered problems such as influence on the existing areas and issues on the existing structures of the area [1].

This study, based on the problems above, analyzes a survey for employees who worked for public institutions before they relocate to the city in terms of democratical elements like gender, age, marital status, and dependants. It then reveals some settlement requirements through the

Article history:

Received (January 25, 2019), Review Result (February 27, 2020), Accepted (April 3, 2020) 
analysis of the employees' level of satisfaction with the requirements. Furthermore, it lays out a plan of positive influx of population the innovative cities in Busan by examining some elements affecting the settlement in the cities.

\section{Theoretical backgrounds}

\subsection{Innovative city}

As for the meaning of 'public organization to be relocated,' it means the public organizations which are to be relocated to regional cities or central administrative agencies determined to be relocated by a Cabinet Council in accordance to the Law on Balanced National Development.

In other words, the innovative city is a made-up cluster of innovations required to achieve regional growth and reinforcement of national competitiveness not only by offering new growth engine for regional cities but also by making a hub for regional growth through the relocation of public organizations. In this case, the relocation is so for the public organizations stipulated in the Law on Balanced National Development except for the ones stipulated on the same law section 18 and its enforcement ordinance section 15. In its regional perspective, the relocation is so for 3 metropolitan cities and 7 provinces except for Chungchungnam-do(province) where a multi-administrative city will be built [2].

On account that the innovative city is composed of innovation subjects (i.e. organizations, universities, and research institutes) [3], a number of facilities making interactive cooperation and networking possible, and many a residential infrastructure, most important are composition of community environment and external and internal network, increased social capital and institutional improvement.

Therefore, the innovative city is not only a city enabling fusion of the interactions among public organizations, business sector, research institutes, and universities but a intelligentnetwork city equipped with tele-communication infrastructure and ubiquitous network making technological innovation and open network possible. In addition, the innovative city is characterized as integrative in that it offers profound educational environment to reinforce innovative capacity and provides residents with eco-friendly atmosphere in which people and nature are reconciled [4].

\subsection{The expected effects of innovative city}

The government anticipated the relocation of public organizations to catalyze the distinct development of region and to raise regional competitiveness, whereby it would contribute to the reinforced national competitiveness.

To maximize the benefits of relocation while securing the basic principle of equitable distribution of public organizations, the government categorized the organization in terms of their functions and made the relocation contribute to the development of regions by considering regional industrial structure, traits and distinct regional policies designed to cultivate strategic industry.

\subsection{Residential settlement}

Residential migration can be defined as an activity of migration which happens in the course that households regulate the consumption of housing.

Because such a migration is a household's process of adaptation to internal or external change of factors such as income level, family composition, residential form and preference to 
housing, the desire to change, eventually is caused by a variety of elements like socio-economic change of environment, the degree of preference to housing, a shift of family composition, whereby a desire to eliminate derivative complaints on the a gap between the level of housing and that of desire can cause the migration [5].

Unlike the migration, the concept of residential settlement is not obviously established, which means there are many a different view in the academic field. This situation being considered, it could be irrational that we can establish a standard regarding residential settlement.

Considering it reasonable that the change of residental migration is closely related to the generation of the migration, the concept of residential settlement is not a fixed one but a flexible one [6].

\subsection{The satisfaction of residential environment}

The level of satisfaction could be different depending on personal traits. In this perspective, the level of satisfaction can be an important standard when examining socio-morphological quality as well as the physical perspectives of residential environment [7].

Provided that house-a basic unit of settlement- is an important part of interest in terms of economic perspectives like investment and value maintenance other than physical, financial and administrative perspectives, expectation theory could be useful to examine the level of satisfaction of economic value on the housing [8]. Furthermore, futuristic value also should be considered in estimating the level of satisfaction.

The estimation from an evaluator about the development possibility of the residential area are profoundly linked to the psychological satisfaction of residence. Therefore, it is also related to the choice of housing and intention to settle in the place with increased preference to and attachment to the area.

The higher the expectation from individuals is on the housing and its quality, the more likely they are to experience higher satisfaction of the settlement [9].

\subsection{Preference and attachment to residential area}

'Preference' is a feeling that favors something in its lexical meaning. As a positive feeling that has been made in the course of communication which satisfies several conditions, preference means a favorable and amicable feeling toward counterparts in the personal relations [10].

Scholars states the conditions for preference to be formed are summed up with the followings: proximity, personal traits, familiarity, compensation, cognitive balance, similarity, and physical attraction. 'Attachment' means a behaviour to maintain relations to beloved others in developmental psychology. Because attachment once formed does not come to be changed easily, it would make consistent effects afterwards [11].

\section{Relocated public organizations and their employee's residential status}

\subsection{The existing status of relocated organization to the innovative cities}

\subsubsection{Nationwide status}

According to An Initiative on the Advancement of Public Enterprises in accordance with the 'Public Institution Advancement Policy' under the Lee Myung Bak administration in 2008, 153 
organizations were designated for the object of relocation in accordance to new designation for integration and adjunct institution: 115 organizations to innovative cities, 19 to self-determined cities and 19 to Sejong.

The number of public organizations to be relocated to 10 innovative cities nationwide was 115 , which was estimated that the policy could create a condition that would promote the development of designated cities by utilizing the competence of public organizations because they were dispersed in accordance to various functions [12].

\subsubsection{Status in Busan}

Busan Innovative City has public organizations associated with 3 function group of video industry, financing, and marine fisheries in Donsam-dong, Munhyun-dong, and Haeundae Centum City respectively. Given that the region is the center of fisheries and port logistics, the policy of innovative city reinforces the function of the city as a continental and marine gateway by basing the newly relocated organizations in the city.

Public organization associated with function of financing such as Korea Exchange and KIBO Korea Technology Finance Corporation were transferred to the city, which enabled it to perform the role of supporting the industries in the south-eastern district and to function as a center of metro-wide economy linked to Busan Free Economic Zone Development. Furthermore, the policy planned the city as a hub of international convention and trade by considering its competence and infrastructure of movie industry within the city.

\subsection{Employees residential status}

\subsubsection{National residence status}

This chapter examines employees' residential status after public organizations located in Seoul were relocated to the innovative cities in June, 2018. 40,548 employees were supposed to be relocated according to the plan. In June, 2018, 38,384 employees were successfully relocated. The other thing to be considered is the number of related companies and that of employees. A study on settlement status of related companies shows that 639 companies were either relocated or newly founded and their employees amount to 11,304 persons. It is a rising number compared to that in December, 2016, when the number of companies were 271 and their employees were 6,965 .

\subsubsection{Residential status in Busan}

The 2016 study shows that among the 2,297 relocated persons 981 persons were the transfer with their dependants and 631 were single or unmarried, which was only $70.2 \%$. The relocated persons with dependants were only $42.7 \%$.

The 2017 study shows a little increase to 2,515 persons. Among them, 1,153 were the persons with dependants and single or unmarried were 699. Compared to that in 2016, the relocated persons with dependants increased by approximately $3 \%$.

The 2018 study shows that among the 2,947 relocated persons, 1,407 persons were the transfer with their dependants which was only $47.7 \%$ among all the persons relocated. It is less than $50 \%$ of the total number of people, which made the city a ghost town on weekends and even coined a new word named 'innovative goose'.

\section{Empirical analysis}


The purpose of this study is to survey the consciousness of relocation of residential workers to innovative cities who moved to local areas according to the public organization relocation plan. Based on the results, it is also planned to analyze how the results of the study above might cause some effects to improve the settlement rate. The study, through the analysis of the results, examines whether there would be any other support measures to improve the rate of family relocation and housing settlement among employees of innovative city relocation institutions other than the supports from the government and city of Busan. In sum, this study is to help the employees settle smoothly and promote the proactive population influx to the Busan Innovative City. What follows below are the result of survey and examination of these above issues.

First, among the relocated employees who reside in Busan, 61.3 percent are the case that they moved alone with no family members, 1.9 percent are the case of partial family migration, and 36.8 percent are that of migration with entire families. Single migration and partial family migration are more than that with entire families.

Second, as for the forms of residential environment, the most common type was company housing (40.6\%). Self-owned housing (32.3\%), lease on deposit basis (20.3\%), and monthly rent (3.9\%) were shown in their order. Apartment were 69 percent, which was most used. As for the price of housing, houses in Busan Innovative City were relatively moderate in their price as responded. The price of housing in Busan was responded as 'moderate' compared to that in other areas.

Third, the reasons why spouse does not want to move to the innovative city were education (25\%), difficulty to reach the workplace (16.5\%) and fear of change of residence (7.7\%). In the evaluation of educational environment, or the biggest reason that made spouses reluctant to move, the persons who responded to 'mediocre' were 54.2 percent which was the highest, those who responded to 'good' were 16.4 percent and those who responded to 'bad' were 29.4 percent.

As a result of the analysis of employees' satisfaction, the comparison of satisfaction between previous residence and the residence in the innovative city shows that they responded to 'mediocre (30\%),' the highest. Unsatisfied (29.4\%) and satisfied (27.1\%) followed. Among the improvements of settlement requirements, traffic environment (32.9\%), education $(24.5 \%)$, cultural and physical education environment $(27.1 \%)$, and residential environment $(12.6 \%)$ were chosen in their order.

To make the priorities regarding the migration of residence, the result of analysis on the response from the first to the fifth priority for the employees' applicable 5 elements shows that the support for business, change of occupation and place-of-work movement is the first priority. The improvement of infrastructure facilities such as culture and hospitals, the improvement of education level, the expansion of housing supply opportunities and benefits, and the expansion of childcare facilities for infants and young children are shown in order.

\section{Conclusion}

This study presents the following implications and suggestions based on various analyses the employee's perception of residential migration through frequency test, cross analysis, correlation analysis, and ANOVA (Analysis of variance).

First, as this study suggests, the employees prefer the migration with some family members or single migration to that with the entire family. Second, among the employees who moved to the innovative city, the unmarried need to be supported in the areas of their spouses' business, turnover, and workplace movements so that they can marry and settle in Busan with their spouses in the future. 
Third, married employees show higher preference on educational environment when asked about the intention of permanent residence. That is why the municipal government needs to improve the level of education by reinforcing the universities and specialized high school.

Fourth, the employees cited the lack of driver's consciousness on safety driving (random driving) and complex road structure as improvements of the traffic environment in Busan. Fifth, a special supply of housing should be made in accordance with the housing factors suited to the employees who transferred to the innovative city.

When it comes to the independent base cities within innovative cities, further research is needed by adding contents not considered in this study.

\section{References}

[1] S. S. Kang and Y. S. Seo, "A study on the existing urban spatial structure affected by innovation city development," Journal of Residential Environment Institute of Korea, vol.14, no.4, pp.215-232, (2016) DOI:10.22313/reik.2016.14.4.215

[2] G. M. Won, "On the success factors of emplementing enovation city," M.S. thesis, Sang-Ji University, pp.2021, (2010)

[3] D. J. Sin, "Significance of the innovative city and future tasks," Planning and policy, vol.297, pp.49-57, (2006)

[4] Y. S. Kwon, "Development and future of innovative city," Journal of Public Officials Benefit Association, vol.41, no.447, pp.22-32, (2006)

[5] J. S. Park, "Research on house relocating selection of public institution workers according to relocation of provincial government building,” M.S. thesis, Dae-Gu University, pp.19, (2014)

[6] N. K. Jo, "An empirical study on residential environmental satisfaction and settlement in area behind industrial complex," Ph.D. dissertation, Mok-Won University, pp.39-46, (2015)

[7] J. G. Son, "The residential satisfaction of residents in high-rise apartments," M.S. thesis, Young-Nam University, pp.6, (2010)

[8] Y. B. Choi, "An analysis of apartment resident satisfaction using a weight applying method," Korean Association of Public Administration, vol.38, no.6, pp.415-440, (2004)

[9] J. S. Lee, "A study on the residential stability of public agencies' employees in the process of their geographical relocation," M.S. thesis, The University of Seoul, pp.8, (2008)

[10] Y. M. Kim, “The effects of hotel customers interpersonal attractiveness on hotel employees' preference and attachment formation,” M. S. thesis, Kyong-Gi University, pp.20, (2013)

[11] J. S. Jang and W. S. Lim, "Research on factors affecting community attachment," Korea Policy Research Institute, vol.15, no.2, pp.101-125, (2015)

[12] S. S. Ryu, "Development of local industries linked with previous public institutions," Planning and policy, vol.439, pp.11-15, (2018) 